\title{
Nuevos discursos en la formación docente en lengua materna y extranjera en Colombia
}

Yamith José Fandiño-Parra

Universidad de La Salle, Colombia yfandino@unisalle.edu.co

\section{Jenny Bermúdez-Jiménez}

Universidad de La Salle, Colombia jbermudez@unisalle.edu.co

\section{Bertha Ramos-Holguín}

Universidad Pedagógica y Tecnológica de Colombia, Colombia

bertha.ramos@uptc.edu.co

\section{Julio César Arenas-Reyes}

Corporación Universitaria Minuto de Dios, Colombia cesararenasreyes@gmail.com

\section{Resumen}

\section{Palabras clave}

El objetivo principal del artículo es proponer un enfoque interdisciplinario y totalizador que permita la transformación de la naturaleza y el alcance del sujeto-docente de lenguas en Colombia, en el marco del posmétodo, las comunidades de práctica, la multialfabetización y la multimodalidad. A través de la revisión documental, se hace un acercamiento teórico a la formación docente en general, para adentrarse en las particularidades de la formación docente en lengua materna y en lengua extranjera. A continuación, se plantea la necesidad de reconfigurar la formación docente en lenguas desde el marco del desarrollo profesional para el empoderamiento. Finalmente, se presentan marcos conceptuales como el posmétodo, las comunidades de práctica, la multialfabetización y la multimodalidad, para proponer posibles aplicaciones en la transformación e innovación de la formación docente en lenguas en Colombia.

Formación de docentes; lengua materna; lengua extranjera; innovación educacional; elaboración del programa educativo (Fuente: Tesauro de la Unesco).

Recepción: 18-03-2015 | Envío a pares: 13-10-2015 | Aceptación por pares: 15-12-2015 | Aprobación: 17-12-2015 


\title{
New Discourses on Native and Foreign Language Training for Teachers in Colombia
}

\begin{abstract}
The primary objective of this article is to propose an interdisciplinary and holistic approach to transforming the nature and scope of language-subject teacher education in Colombia, in the era of post-method language teaching, communities of practice, multi-literacies and a multimodal approach. Through a document review, a theoretical approach to teacher training in general is established, before delving into the specifics of educating teachers in their mother tongue and a foreign language. The need to reshape teacher training in languages from the standpoint of professional development for empowerment is proposed, and conceptual frameworks such as post-method teaching, communities of practice, multi-literacies and a multimodal approach are presented as possible applications to transform and innovate language teacher training in Colombia.
\end{abstract}

\section{Keywords}

Teacher training; mother tongue; foreign language; educational innovation; educational program development (Source: Unesco Thesaurus). 


\section{Novos discursos na formação docente em língua materna e estrangeira na Colômbia}

Resumo

O objetivo principal deste artigo é propor um enfoque interdisciplinar e totalizador que permita a transformação da natureza e o alcance do sujeito-docente de línguas na Colômbia no âmbito do pós-método, das comunidades de prática, da multialfabetização e da multimodalidade. Por meio da revisão documental, faz-se uma aproximação teórica à formação docente em geral, para, em seguida, tratar das particularidades da formação docente em língua materna e em língua estrangeira. $\mathrm{Na}$ sequência, apresenta-se a necessidade de reconfigurar a formação docente em línguas a partir do desenvolvimento profissional para o empoderamento. Finalmente, expõem-se referenciais conceituais como o pós-método, as comunidades de prática, a multialfabetização e a multimodalidade, para propor possiveis aplicações na transformação e na inovação da formação docente em línguas na Colômbia.

\section{Palavras-chave}

Formação de docentes; língua materna; língua estrangeira; inovação educacional; elaboração do programa educativo (Fonte: Tesauro da Unesco). 


\section{Introducción}

El uso eficiente tanto de la lengua materna como de las lenguas extranjeras es uno de los compromisos más importantes del sistema educativo. A través de ellas no solo creamos un universo de significados y sentidos de la realidad que nos rodea, sino que comunicamos la riqueza de sentimientos e ideas de nuestro mundo interior. En últimas, establecemos y mantenemos relaciones sociales y construimos espacios para su difusión y mejoramiento. Las lenguas se configuran, entonces, en elementos fundamentales del desarrollo humano en un mundo cada vez más global, interdependiente y complejo.

En el mundo de hoy, los nuevos discursos en la pedagogía de las lenguas se han configurado en oportunidades para entender más profundamente la compleja relación entre lenguaje-pensamientoaprendizaje-cultura. Estos discursos han dado pie a que los programas de formación busquen trascender la implementación de planes de estudios orientados hacia la cualificación del trabajo con habilidades y competencias para adentrarse en la consolidación de propuestas formativas encaminadas a la producción de conocimiento en torno a mediaciones socioculturales y estudios semióticos discursivos. Dichas propuestas pueden potenciar sus alcances al implementar marcos epistemológicos y metodológicos derivados del posmétodo y las comunidades de práctica.

Por otra parte, las nuevas tecnologías de la información y comunicación (TIC) se constituyen en mediaciones novedosas para navegar el mundo y la realidad. A través de ellas, los seres humanos podemos, además de intercambiar información de manera instantánea, construir nuevas formas o modos de expresión, ya no solo escrita u oral, sino digital e hipermediática. Su uso creciente exige el trabajo sistemático de habilidades que permitan la adquisición exitosa de nuevos procesos formativos basados en la multialfabetización y la multimodalidad.
Como resultado del vertiginoso desarrollo de la pedagogía en lenguas y de la creciente presencia de las TIC, es necesario examinar las prácticas de formación docente, con el propósito de reinterpretar y redireccionar las propuestas de las facultades de educación, los programas de licenciatura y los procesos de cualificación docente. Este artículo hace una revisión teórica de la formación docente en general, para analizar las particularidades de dicha formación en lengua materna y en lengua extranjera. A continuación, se plantea la necesidad de reconfigurar la formación docente en lenguas desde el marco del empoderamiento docente. Finalmente, se presentan marcos conceptuales como posmétodo, comunidades de práctica, multialfabetización y multimodalidad, y se proponen posibles aplicaciones en la transformación e innovación de la formación docente en lenguas.

\section{Formación docente}

\section{Definición y perspectivas}

La Unesco (1990) declara que la formación docente se refiere tanto a programas de pregrado como de posgrado que siguen un proceso continuo de experiencias formales y no formales, orientadas al desarrollo profesional del profesorado. Al respecto, Villegas-Reimers (2002) define la formación docente como un proceso a largo plazo que incluye oportunidades y experiencias planificadas sistemáticamente para promover el crecimiento y el desarrollo en la profesión. Para Cochran-Smith y Zeichner (2009), la formación docente se lleva a cabo en comunidades e instituciones en las cuales los componentes y las estructuras de los programas interactúan tanto con las experiencias y habilidades que los docentes tienen como con las políticas y las condiciones que los Estados imponen.

Al analizar la formación docente, Loughran (2006) dice que esta tiene dos focos fundamentales: el aprendizaje sobre la enseñanza y la enseñanza de la enseñanza. Estos focos involucran la adquisición 
y el desarrollo de una amplia serie de habilidades, conocimientos y competencias. Además, estos focos se complejizan por tensiones cognitivas y afectivas presentes en la práctica, que influyen en el aprendizaje y el crecimiento profesional (pp.5-8).

Por su parte, Feiman-Nemser (1990) habla de cinco posiciones teóricas y metodológicas acerca de los objetivos, los medios y los fines de preparación de los maestros. En su opinión, estas orientaciones conceptuales reflejan el énfasis que los distintos programas dan a diferentes aspectos de la formación docente. Las cinco orientaciones conceptuales son: a) la orientación tecnológica, la cual hace hincapié en el conocimiento científico y la instrucción sistematizada; b) la orientación práctica, la que hace hincapié en la sabiduría de la práctica y el aprendizaje derivado de la experiencia; c) la orientación personal, que presta atención especial al profesor como persona y al alumno, al sugerir que el desarrollo personal es una condición previa para la enseñanza; d) la orientación académica, la cual hace énfasis en el papel del profesor como un líder intelectual y e) la orientación crítica, que se centra tanto en cuestionar los supuestos sobre la enseñanza, el aprendizaje y el conocimiento como en crear aulas que reflejen principios democráticos (pp. 217-220).

A pesar de su riqueza conceptual, la formación docente está viviendo un momento desafiante, tanto en lo que respecta a la preparación inicial de profesores como en lo concerniente a cualificación de profesores en ejercicio. Para Adler (2004), este desafío se presenta porque el Estado y la sociedad esperan que las escuelas logren que todos los estudiantes aprendan y se desenvuelvan con altos niveles de desempeño. Sin embargo, estos estamentos no reconocen la compleja realidad de escuelas llenas de estudiantes, con una creciente gama de necesidades y exigencias formativas. Al quedar en medio de las exigencias sociales y la complejidad escolar, la formación docente se ve abocada a ofertar programas cuyos planes de estudio instruyen en una serie estandarizada de saberes, habilidades y actitudes ajustables a necesidades e intereses transitorios. Al respecto, Vieira y Moreira (2008) afirman que la formación docente todavía tiende a decirles a los maestros qué y cómo hacer las cosas (instrucción técnica) en lugar de facilitar un conocimiento profundo y una intervención decidida de los contextos educativos (investigación reflexiva). Este estado de cosas plantea restricciones sobre la reflectividad, la autenticidad, la interacción dialógica, la apertura a la innovación y la autonomía.

En el contexto nacional, la situación de la formación docente resulta contradictoria como resultado de la implementación del Estatuto de Profesionalización Docente, consignado en el Decreto 1278 de 2002. Para Álvarez y León (2008), este decreto plantea un proyecto político pedagógico que, por una parte, habla de la necesidad de preparar profesores idóneos para el ejercicio de la profesión docente pero, por otra, establece que un profesional no docente puede desempeñar con idoneidad procesos de enseñanza-aprendizaje al cursar por un año un programa de pedagogía en una institución de educación superior. Para estos autores, este planteamiento va en contravía de una tradición histórica de esfuerzos estatales y apuestas pedagógicas, orientados hacia la cualificación de la formación y el desarrollo docente en Colombia. Álvarez y León sostienen que la naturaleza y el alcance de este Estatuto contraviene "la historia, las políticas internacionales, y sobre todo, la posibilidad de garantizarles a las nuevas generaciones una escuela capaz de responder a su presente" (p. 68).

\section{Formación docente en lengua materna (FDLM)}

Al hablar de formación en lengua materna, Díaz-Corralejo (2002) sostiene que el aprendizaje de lengua, literatura y cultura debe tener como soporte básico el texto en todas sus categorías. Para él, la formación debe tener como propósito fundamental el dominio funcional del lenguaje y como fines secundarios: la formación comunicativa, la construcción 
de las funciones sociales, el análisis y la reflexión, entre otros. Igualmente, afirma que el trabajo con lengua y texto debe ser complementario de manera que se forme tanto en lo individual como en lo social, en la función específica del texto como en su relación con los demás textos y en el conocimiento social específico del entorno textual y literario como en el conocimiento general de la humanidad. En resumen, Díaz-Corralejo afirma que el trabajo con lengua castellana se debe entender como un proceso de enseñanza-aprendizaje de acceso y construcción del sentido a través de la lengua, la literatura y la cultura.

Al respecto, Pérez, Barrios y Zuluaga (2010) discuten una serie de rasgos que caracterizan la formación en lengua materna en Colombia. Afirman que se evidencian propuestas que privilegian los propósitos académicos del docente sin hacer del gusto o el placer del estudiante un fin; situación que puede resultar contraproducente en el ámbito afectivo y contextual. Por otra parte, hablan de la presencia de un trabajo adecuado a la comprensión y producción de unidades complejas de lenguaje como el texto, pero que indica un excesivo énfasis en la narración, una escasez de contacto con otros géneros textuales y un reducido trabajo sistemático con la literatura y el lenguaje oral. Igualmente, los autores hablan del predominio del uso de materiales impresos, lo que redunda en una escasa presencia de recursos mediados por las TIC. Además, estos investigadores muestran que a pesar de existir la preocupación por el desarrollo de competencias comunicativas en los estudiantes, se ve una insuficiencia en cuanto a mecanismos, instrumentos y estrategias de seguimiento y evaluación de los aprendizajes.

Por su parte, Arnáez (2006) explica que en el terreno de la formación en lingüística contrastan altas metas teóricas de corte psicolingüístico, sociolingüístico, pragmático y discursivo con las vivencias de la práctica diaria; esta situación desemboca en dificultades para estructurar y articular el trabajo docente con diferentes tipos de textos y situaciones comunicativas. Para este autor, la preocupación por implementar los recientes avances disciplinares en la enseñanza de la lengua materna termina por ignorar la cuestión de la aplicabilidad de las teorías en el trabajo del salón de clase; específicamente, cuando no se hace el desarrollo adecuado de métodos. En consecuencia, Arnáez argumenta que la formación docente en lengua materna debe buscar la reflexión sobre tres grandes dicotomías que surgen de la implementación de diversas concepciones y modelos de aplicación: estructura (competencia lingüística) frente a uso (competencia comunicativa); deber ser (teoría) frente a ser (práctica) y enseñar lengua frente a enseñar gramática. Igualmente, al hablar de la enseñanza de la lengua, Arnáez (2013) discute sobre la necesidad de abordar algunas subáreas cuyo desarrollo considera relevante en la formación docente: producción y comprensión oral, expresión escrita, comprensión lectora, didáctica de la competencia comunicativa y análisis del contexto sociocultural y educativo.

Similarmente, Flores y López (2011) discuten el problema que existe entre la relación del desarrollo de las ciencias del lenguaje y su aplicación a la pedagogía y la didáctica de la lengua. Para ellos, se presentan limitaciones cuando se pretende sustituir la enseñanza tradicional (memorización de reglas y aplicación de estructuras) por metodologías modernas (orientación hacia la competencia comunicativa y presunción de metalenguaje). Estas limitaciones hacen necesario el estudio de la política educativa de los contenidos curriculares, las estrategias didáctico-pedagógicas para la enseñanza de la lengua y la revisión de la formación de los docentes para hacer la política viable. Más concretamente, para estos autores, la formación docente deberá analizar e interpretar estas limitaciones de manera que el profesor de lengua materna pueda estudiar las consecuencias de privilegiar en demasía la perspectiva comunicativa sobre la enseñanza gramatical así como el lenguaje cotidiano sobre la lengua estándar.

Desde la perspectiva de la FDLM, Londoño (2003) afirma que esta conlleva como mínimo el co- 
nocimiento en pedagogía y en lingüística. La pedagogía permite abordar la lengua de una manera más eficiente y efectiva a la hora de didactizar el saber con los estudiantes. La lingüística, por su parte, aporta las bases teóricas sobre el concepto de lengua, sus funciones y sus unidades de análisis. A pesar de esta distinción, Londoño señala que para los profesores en Colombia es difícil romper con la fuerte tradición lingüística que los ata a concepciones tradicionales de la gramática. Incluso, sostiene que aquellos profesores que tienen perspectivas estructuralistas o generativistas transformacionales suelen no superar el trabajo con la oración en situaciones descontextualizadas. A pesar de esta situación, Londoño indica que se perciben esfuerzos individuales e institucionales por propender por una gramática del texto y análisis del discurso, con una concepción pragmática sobre la comunicación como espacio de encuentro y producción discursiva. En últimas, esta situación lleva a replantear no solo el trabajo en el aula de clase de lengua castellana para que el estudio se haga a través de análisis creativos de los diferentes textos que rodean a los estudiantes, sino que, sobre todo, exige formación centrada en el desarrollo de procesos de comprensión y producción de sentidos y conocimientos basados en la generación de prácticas sociocomunicativas en pro del crecimiento del ser humano.

Por su parte, la propuesta del Ministerio de Educación Nacional (2006) sugiere el trabajo con y desde tres campos fundamentales con la FDLM: pedagogía de una lengua castellana, pedagogía de la literatura y pedagogía de otros sistemas simbólicos; estas pedagogías se deben abordar desde una mirada multidisciplinaria para el mejor desarrollo de las competencias del lenguaje. La primera pedagogía implica contemplar el desarrollo de la competencia comunicativa no solo a través del estudio de los rasgos formales del castellano sino de la contemplación de sus implicaciones en los órdenes cognitivo, pragmático, emocional, cultural e ideológico. La segunda pedagogía busca consolidar una tradición lectora a través de la generación de procesos metódicos que promuevan el gusto por diferentes tipos de textos de manera que se enriquezca la visión de mundo. La tercera conlleva el abordaje integral de dimensiones verbales y no verbales que permitan expresión e interacción exitosas con el entorno. En últimas, el trabajo sistemático con estas pedagogías permitirá la formación de docentes de lengua materna capaces de potenciar el desarrollo lingüístico, comunicativo y cognitivo de los estudiantes a través de su paso por el sistema educativo colombiano.

\section{Formación docente en lengua extranjera (FDLE)}

De acuerdo con Johnson (2009), la formación docente en lengua extranjera (FDLE) ha sido influida por diferentes tendencias que han reconceptualizado la manera como las personas definen a los profesores de lenguas extranjeras, su aprendizaje y su enseñanza. En su opinión, estas tendencias se han visto impulsadas por un desplazamiento epistemológico sobre el aprendizaje, en general, y sobre el aprendizaje de lenguas y el trabajo del profesor de lenguas extranjeras, en particular. Este desplazamiento se ha dado desde posiciones centradas en el conductismo y el cognitivismo, hacia perspectivas de corte sociocultural e interaccionista acerca de la condición humana. Como resultado, la FDLE ha pasado de conceptualizarse como el simple adiestramiento de un instructor capacitado para aplicar la teoría sobre lenguas en el salón de clase, a asumirse como la preparación de un creador de formas legítimas de conocimiento capaz de tomar decisiones sobre cómo enseñar según los complejos contextos sociales, culturales e históricos que lo rodean. En otras palabras, explica Johnson, la FDLE ya no debe ver la enseñanza de lenguas como la mera traducción de teorías a prácticas efectivas de instrucción, sino como un proceso dialógico de co-construcción de conocimiento que surge de contextos socioculturales, situados histórica y políticamente.

Al hablar de FDLE, Richards (1998) afirma que no hay consenso acerca de cuáles son las bases con- 
ceptuales esenciales para la preparación del profesor de lenguas extranjeras. Sin embargo, en un esfuerzo por determinar los contenidos curriculares apropiados y los procesos instruccionales efectivos, Richards propone seis ámbitos básicos como el sustrato teórico de la FDLE: teorías sobre la enseñanza (principios teóricos que fundamentan la enseñanza y las prácticas de aula), habilidades para la enseñanza (dimensiones esenciales del repertorio instruccional de cualquier maestro), habilidades para la comunicación (competencia en el dominio del idioma y el intercambio de información), conocimiento disciplinar (conocimiento disciplinario especializado de la enseñanza de lenguas extranjeras), razonamiento pedagógico y toma de decisiones (habilidades cognitivas y de resolución de problemas que sustenten las prácticas pedagógicas) y conocimiento contextual (información sobre políticas educativas y lingüísticas, así como datos relacionados con estudiantes, instituciones y programas). Para Richards, el desarrollo sistemático y crítico de estos seis ámbitos puede ayudar a los docentes en formación y en ejercicio a entender las realidades del salón, mejorar sus experiencias educativas y, en últimas, estimular la reflexión crítica y la transformación.

En una perspectiva similar, González y Quinchía (2003) sostienen que la FDLE se ha enfocado hacia el desarrollo de cuatro áreas básicas: 1) el dominio de la lengua, 2) el conocimiento sobre la enseñanza de la lengua, 3) la experiencia con investigación y 4) el contacto con la realidad local. El trabajo sistemático y continuo con estas dimensiones busca, entre otras cosas, permitirle a los profesores alcanzar altos niveles de competencia comunicativa y construir conocimiento en la disciplina para lograr enseñar en variados contextos a poblaciones disimiles. Para estas autoras, el propósito fundamental de la formación debe ser ofrecer a los docentes los saberes, las habilidades y las actitudes necesarias para que sean sensibles a las condiciones particulares del medio sociocultural en el cual tiene lugar el proceso de enseñanza-aprendizaje.
Por su parte, Cárdenas (2009) sostiene que la FDLE no debe proveer a los docentes en formación y en ejercicio de elementos que correspondan a un único modelo, sino que, por el contrario, debe facilitar el desarrollo de una cualificación acorde con la gran diversidad de posibilidades de trabajo, el constante cambio en el campo de la enseñanza y las crecientes necesidades de los estudiantes. En concreto y al retomar a Freeman, Cárdenas sostiene que el uso simultáneo de elementos de todos los modelos formativos es necesario para que los docentes de lenguas extranjeras puedan desarrollar interenseñanza, un movimiento desde etapas de dependencia, recepción de información y asesoría hacia una práctica eficaz, creativa y autosuficiente (ver Freeman, 1991, p. 1). En conclusión, Cárdenas aboga por una FDLE que le permita al profesor construir su saber y experiencia a través de un proceso gradual que lo lleve de ser un aprendiz a convertirse en un pedagogo investigador.

En Colombia, Usma (2009) sugiere que la búsqueda de la estandarización, la internacionalización y la acreditación han minado las posibilidades de la FDLE para reconocer y promover el conocimiento, la autonomía, la diversidad y la contextualización. Para él, estas decisiones y regulaciones no solo han impuesto discursos y prácticas foráneos a expensas de los conocimientos locales, sino también han estratificado y excluido a los profesores e instituciones basados en puntajes y clasificaciones. Como resultado, la FDLE en Colombia se ha visto obligada a cumplir con requisitos surgidos de discursos tradicionalistas, los cuales desestiman el conocimiento de los profesores y restringen la reflexión e interacción.

Ahora bien, sin importar si se está hablando de formación docente en lengua materna o lengua extranjera, la premisa que permea este artículo es que la presencia de las TIC y la existencia de nuevos discursos en la pedagogía de las lengua requieren de una reconfiguración o redireccionamiento de los programas de pregrado y posgrado en Colombia. Esta innovación o transformación curricular no 
consiste simplemente en incorporar nuevos enfoques teóricos o prácticas metodológicas; al contrario, exige replantear la misión, la visión y el proyecto educativo de las universidades colombianas con el fin de empezar la construcción de un enfoque interdisciplinario y totalizador que permita no solo la creación de apuestas formativas basadas en el desarrollo profesional para el empoderamiento docente, sino, sobre todo, la transformación de la naturaleza y el alcance del sujeto-docente de lenguas en Colombia en el marco del posmétodo, las comunidades de práctica, la multialfabetización y la multimodalidad.

\section{Desarrollo profesional y empoderamiento docente}

En términos generales, el desarrollo docente es el crecimiento profesional que un profesor logra al adquirir experiencia y examinar metódicamente su enseñanza. Este crecimiento resulta del movimiento a través de los diferentes ciclos de la vida profesional, sobrepasando así la simple toma de programas de cualificación. Más concretamente, el desarrollo profesional se puede entender como un proceso a largo plazo que incluye la planeación de oportunidades habituales y sistemáticas que fomenten el progreso docente (Glatthorn, citado por VillegasReimers, 2003, p. 11).

Sin embargo, la premisa que aborda este documento es la creencia de que el desarrollo docente en lengua materna y extranjera no se debe realizar simplemente para satisfacer las demandas de la sociedad actual o para hacer frente a las preocupaciones del sistema educativo. Aunque necesarios, estos objetivos son limitados, ya que principalmente el desarrollo docente debe permitirle a los profesores de lengua materna y extranjera tomar el control de sus propias vidas y acrecentar o profundizar su competencia profesional. Sobre este particular, Whitehead (1989) afirma que los profesores pueden y deben desarrollarse profesionalmente mediante la celebración de un diálogo interno, crítico y sistemático para entender sus propias prácticas y circunstancias. El desarrollo docente, por tanto, necesita moverse de formas proposicionales de la teoría, que se limitan a ver los hechos, hacia formas dialécticas de la teoría que muestran cómo las personas explican sus acciones en términos de sus propios valores e intenciones. En consecuencia, retomamos la propuesta de Fandiño (2010), quien entiende el desarrollo docente como:

...un proceso de autodescubrimiento, actualización y cumplimiento en el cual los profesores se configuran tanto como conocedores activos, responsables de la exposición de sus puntos de vista acerca de la naturaleza de sus vidas profesionales, como agentes críticos, capaces de actuar sobre ese conocimiento para transformar sus prácticas y circunstancias (p.112).

De esta manera, el desarrollo docente en lengua materna y extranjera debe entenderse como un proceso de autoexamen que ayuda a los profesores a convertirse en conocedores dinámicos y agentes analíticos, capaces de comprender cómo y por qué hacen lo que hacen, y preparados para comunicar sus hallazgos y conclusiones para el beneficio propio y el de los demás. Es, en otras palabras, un proceso que debe proporcionar empoderamiento a los profesores. Los siguientes párrafos desarrollan el concepto de empoderamiento docente.

En este artículo, el empoderamiento docente no se refiere a simples acciones formativas para aumentar el conocimiento del profesor de lengua materna o lengua extranjera, porque una mayor preparación del docente no se traduce directamente en una mayor influencia en las decisiones que afectan su capacidad para enseñar. Esta mayor preparación tampoco le permite al profesor desafiar la estructura jerárquica del status quo en el cual él no es más que el medio por el cual el sistema ejerce su voluntad en el aula. Retomando a Romanish (1993), creemos que se debe asumir el empoderamiento docente como la validación de la función y la autoridad de la experiencia del maestro de manera que pueda superar barreras en el ejercicio legítimo de su práctica. Esta 
definición exige que las escuelas se asuman como sitios para la creación de procesos dialógicos y prácticas democráticas que garanticen la validación de la experiencia, la capacidad de decisión y la voz del profesor en las prácticas y circunstancias escolares (Romanish, 1993, p. 53).

Al respecto, Short (1994) sostiene que el empoderamiento docente es un constructo teórico que integra la competencia personal y profesional de los profesores con entornos educativos que proporcionan oportunidades para desplegar esa competencia. Este constructo implica que, por un lado, los profesores crean que tienen las habilidades y los conocimientos para actuar y mejorar la situación educativa $y$, por otro, las escuelas provean oportunidades para que sus habilidades y conocimientos se desarrollen y visualicen. Así, el empoderamiento docente es un proceso mediante el cual los actores escolares desarrollan su competencia para hacerse cargo de su propio crecimiento y para resolver sus propios problemas, mientras que los sistemas escolares aumentan la capacidad de distribuir los roles en la toma de decisiones y aumentar las oportunidades de participación significativa y colectiva (p.489).

Al hablar de empoderamiento docente, Martínez (2008) sostiene que este puede llegar a ser visible a través de la investigación y la innovación porque asumir la práctica educativa como objeto de reflexión produce un efecto en la subjetividad de los docentes que aumenta su capacidad de análisis, observación y conocimiento. La consistencia y la fuerza en la innovación y la investigación empoderan a los profesores, puesto que estas actividades los posicionan como profesionales que pueden producir conocimiento acerca de la educación y ejercer poder sobre ella. Para Martínez, el asumir la investigación y la innovación con rigor no solo ayuda a los profesores a desarrollar habilidades científicas, críticas y comunicativas, sino que también, y mejor aún, les ayuda a construir saber pedagógico, ${ }^{1}$ el cual, en última ins-

$1 \quad$ Conjunto de conocimientos con estatuto teórico o práctico que conforman un dominio de saber institucionalizado, el tancia, produce una transformación de las prácticas y los procesos. De este modo, el empoderamiento docente les permite a los profesores ser sujetos de conocimiento, reconocidos y seguidos por otros, una situación que facilita el surgimiento de asociaciones o redes de maestros (p. 3 ).

Las propuestas de Whitehead (1989), Romanish (1993), Short (1994) y Martínez (2008) nos ofrecen un interesante marco conceptual en el que el empoderamiento docente se comprende como un proceso mediante el cual los profesores de lengua materna y extranjera desarrollan, incrementan y validan su experiencia, su toma de decisiones y su autoridad con el fin de tener una voz efectiva en sus prácticas y circunstancias educativas. Así entendido, el empoderamiento docente ayuda a los profesores de lenguas a ejercer poder en sus vidas educativas, resistir los mecanismos de control y transformar el sistema formativo, lo cual en última instancia desafía la estructura jerárquica del status quo educativo. A través de este tipo de empoderamiento docente, los profesores de lenguas pueden ampliar su voz o discurso sobre asuntos educativos, construir teoría educativa viva ${ }^{2}$ y generar saber pedagógico.

De esta manera, creemos importante que los programas de formación docente, tanto en lengua materna como lengua extranjera en Colombia, aboguen por apuestas educativas que posibiliten el empoderamiento de profesores de lenguas como conocedores activos y agentes críticos. En otros términos, este empoderamiento debe facilitar el inicio de procesos innovadores para transformar sus prácticas y realidades educativas y para construir un saber pedagógico propio. Estos procesos pueden, en últimas, permitirles a los profesores de lengua materna y extranjera no solo cuestionar y resistir mecanismos de regulación y control, sino tomar las

cual configura la práctica de la enseñanza y la adecuación de la educación en una sociedad (Zuluaga, 1999, p. 149).

2 Una forma de desarrollo profesional docente basada en el cuestionamiento constante de por qué uno hace las cosas que hace y cómo puede mejorar lo que se hace (Whitehead, 1989, p. 24). 
riendas de sus vidas para desarrollar sus competencias profesionales a través de la reflexión y la investigación.

Ahora bien, la pregunta que cabe hacerse es cómo lograr este empoderamiento docente y hacia qué nuevos terrenos debemos orientarlo. Inicialmente, proponemos implementar el posmétodo y las comunidades de práctica como marcos conceptuales de los programas de formación tanto de pregrado como posgrado en Colombia. Por otra parte, consideramos necesario explorar la multialfabetización y la multimodalidad como nuevos horizontes educativos para las apuestas formativas. En los siguientes párrafos se dan elementos para tener una comprensión básica de estos referentes conceptuales.

\section{Marcos conceptuales}

\section{Posmétodo}

Kumaravadivelu (2003) plantea que, ante la dificultad de encontrar una conceptualización adecuada para el constructo método, y ante la multiplicidad de métodos disponibles, no se debe buscar otra metodología, sino una alternativa al concepto. Concretamente, afirma que: "alternatives to method are mainly products of bottom-up processes" (p. 33); es decir, la tarea actual no consiste simplemente en realizar un cambio de terminología, sino en iniciar un cambio de paradigma. En este nuevo paradigma, se busca que los docentes construyan sus propias teorías y prácticas, de manera que estas les permitan generar estrategias específicas para sus aulas particulares. Este paradigma implica mucha autonomía por parte del docente, la cual se debe reflejar en lo institucional y lo curricular, a través del uso crítico de macroestrategias de enseñanza y en el compromiso con observarse, analizarse y evaluarse para llevar a cabo los cambios que se consideren pertinentes. Además, este paradigma está ligado a la implementación del llamado pragmatismo con principios, en donde toda teoría se actualiza en y desde la práctica real en el salón de clase.
Muchos estudiosos se refieren a la era actual como la del posmétodo, entendido este como una aproximación en la cual es importante tener en cuenta los principios que guían el aprendizaje, localizado en un contexto determinado. Tales principios, aplicados en contextos particulares, contribuirán al éxito del programa de aprendizaje de los estudiantes según sus necesidades e intereses. Igualmente, estos principios cumplirán la función de base del programa de enseñanza aplicado al aula (Foppa, 2011).

Kumaravadivelu (citado por Cruz-Arcila, 2013) plantea el concepto de posmétodo con el propósito de incorporar en la enseñanza de lenguas nuevos parámetros como la particularidad, la practicidad y la posibilidad. La particularidad se refiere al hecho de que se debe pensar una pedagogía para un profesor particular, con estudiantes en un ambiente específico, que tienen unos objetivos y un contexto sociocultural determinados. Así, en el proceso de enseñanza-aprendizaje, la idea es tener en cuenta las necesidades concretas, locales. Por su parte, la practicidad se da por la necesidad de tener resultados de investigaciones para tomar decisiones informadas. Al respecto, la investigación-acción parece ser la más adecuada, pues examina las particularidades de cada contexto para, a través de acciones sistemáticas de reflexión y observación, planeación, acción y evaluación, crear el mejor contexto posible de aprendizaje (p. 85). Finalmente, la posibilidad se refiere al conocimiento que los docentes deben tener del contexto sociocultural de los estudiantes para proveer la posibilidad de integrar estas condiciones al salón de clase, así como también entender las necesidades lingüísticas de los alumnos para trabajar sobre ellas de manera consciente. La idea es crear conciencia no solamente de sus propias condiciones sociales, sino de la capacidad que tienen para cambiar la realidad.

En este orden de ideas, la enseñanza en el marco de la pedagogía posmétodo se muestra como un modelo adecuado a los cambios tecnológicos que se han dado y que llevan al planteamiento de la mul- 
tialfabetización, pues para elaborar programas e integrar este concepto se requiere de docentes que sean capaces de realizar investigaciones de aula que les permitan diseñar estrategias y programas multialfabéticos y de utilización de nuevas tecnologías realistas, situados en sus comunidades particulares y con una visión crítica que propenda por el mejoramiento y la cualificación de la realidad en la cual se encuentran los estudiantes (ver Meneghini, 2009).

\section{Comunidades de práctica}

Comunidad de práctica es un concepto que viene de la sociología, en donde se entiende como un grupo de personas que, con diversas habilidades y destrezas, tienen un objetivo común y aportan a la consecución de dicho objetivo de la mejor manera posible, cada uno desde sus propias habilidades y particularidades. En términos de Yang:

The nature of the community of practice, its goals, and its communicative procedures are all co-determined by the individual members in a way that allows for continuous change and selfdevelopment. In consequence, a community of practice usually serves as an effective platform for people to exchange knowledge and localize new information based on their personal needs and living environment (2008, p. 12).

Hourdequin (2012) llama la atención sobre otra de las características de las comunidades de práctica: su evolución en el tiempo. Los miembros de la comunidad de práctica evolucionan a través de la historia del grupo. El foco de atención es más la participación que la adquisición. El concepto de comunidad de práctica se ha usado para observar y analizar las interacciones de los estudiantes de lenguas en el complejo proceso de convertirse en participantes en diversas colectividades o asociaciones. Lo interesante es que en muchos casos, las comunidades de práctica son lideradas por personas que no necesariamente son hablantes nativas de la lengua objetivo.
En la formación de docentes de lenguas, las comunidades de práctica se han utilizado para reflexionar acerca del quehacer docente. Estas comunidades se han extendido en el tiempo y el espacio gracias a las nuevas tecnologías que se han utilizado para crear grupos de interés que intercambian sus experiencias docentes y que tratan, de manera conjunta, de mejorar sus prácticas en todos los niveles, desde la planeación hasta la evaluación (Yang, 2008).

Las nuevas tecnologías brindan espacios virtuales en donde las comunidades de práctica se pueden reunir para intercambiar información de toda índole sobre el proceso de aprendizaje. Dentro del abanico de posibilidades que brindan las TIC, tal vez el más utilizado para crear comunidades de práctica es la creación de blogs. Estos son espacios que se han constituido en herramientas que, por un parte, crean comunidades para efectos de mejorar el ejercicio educativo entre docentes $y$, por otra parte, ofrecen herramientas de desarrollo de habilidades de los discentes, quienes pueden interactuar académicamente con pares de cualquier parte del mundo.

\section{Multialfabetización}

En los últimos años del siglo XX, un grupo de investigadores en pedagogía, The New London Group, desarrolló el concepto de multialfabetización. La multialfabetización hace referencia a las diversas formas de alfabetización que se necesitan en el mundo contemporáneo, globalizado, profundamente multicultural y plurilingüe. En términos del grupo:

We want to extend the idea and scope of literacy pedagogy to account for the context of our culturally and linguistically diverse and increasingly globalised societies; to account for the multifarious cultures that interrelate and the plurality of texts that circulate... we argue that literacy pedagogy must account for the burgeoning variety of texts forms associated with information and multimedia technologies (The New London Group, 2000, p. 9). 
Así pues, la Pedagogía de la Alfabetización, que se centraba en los procesos de enseñanza-aprendizaje de textos escritos en libros monolingües, escritos en la variedad estándar de la lengua, perteneciente a la comunidad hegemónica que produce y controla los discursos oficiales, debe ampliar su ámbito de acción para incluir diversas variedades y lenguas habladas o consideradas necesarias en el grupo, textos culturalmente distintos y textos provenientes de los diversos y complejos mundos de las tecnologías multimedia y de la información. Esto incluiría textos no solamente en el registro estándar, sino en los disímiles dialectos regionales y locales de la lengua oficial: textos en las lenguas mayoritarias cuyo conocimiento se considere necesario o deseable; en las lenguas minoritarias que hagan parte del acervo cultural de la comunidad; aquellos provenientes de las plataformas multimediáticas, y textos visuales y gráficos que interactúan con textos escritos en los múltiples medios de información disponibles en el momento.

Los efectos de estas reflexiones acerca de la Pedagogía van a afectar directamente el mundo laboral, el ejercicio de la ciudadanía y la vida privada de los miembros de las comunidades. Se puede pensar que la diversidad cultural y lingüística, tanto en términos de lenguas como de dialectos y sociolectos, se puede analizar como una riqueza explotable en términos laborales, pues se espera que la producción posfordista, que ya no pretende tener obreros de línea de producción en serie sino personal capacitado para resolver problemas y para producir resultados integrales, sea un lugar más propicio para la valoración de la diferencia cultural y lingüística.

Ahora bien, esta diversidad no se debe interpretar como la ausencia de formación en las variedades oficiales o en el manejo de la lengua estándar, se trata de una comprensión de los complejos fenómenos socioculturales que llevan a las personas a identificarse consciente o inconscientemente con subgrupos más o menos alejados de la cultura dominante. Como se trata de crear equipos de trabajo cooperativo, el uso de elementos culturales y lingüísticos no estándares puede de hecho constituir un valor positivo en la realización de tareas para ser llevadas a cabo por grupos de personas. En el campo de la ciudadanía, la expansión del pluralismo cívico implica la negociación de otro orden social en donde las diferencias deben ser reconocidas y valoradas positivamente, y donde la gente debe tener acceso a un repertorio cultural y lingüístico más amplio. En la vida personal, se está desintegrando la idea del "público" como un ente homogéneo, como una "comunidad imaginada", esto debido a las muy diversas ofertas de información multicanal que les posibilitan a las personas tener un universo informativo mucho más personalizado. A pesar de todo esto, hay una homogeneización en el consumo, sobre todo en los niños y jóvenes que quieren tener objetos de consumo similares en múltiples partes del mundo. También, se presenta una "conversalización" de la vida privada de las personas (The New London Group, 2000), cuando ventilan asuntos privados a través de los diversos canales y las redes sociales existentes.

La presencia de nuevas formas de comunicación implica mayores posibilidades para que grupos e individuos puedan encontrar una voz en los nuevos medios multimodales. Esta multiplicidad de posibilidades de pertenecer a diversas comunidades (profesionales, académicas, políticas, de orientación sexual, etc.) impulsa el surgimiento de nuevas prácticas que no solo se contraponen con los discursos hegemónicos, sino que se actualizan día tras día al interactuar en múltiples escenarios sociales y culturales. Como resultado, el trabajo con la multialfabetización exige la inclusión, en los programas de formación de docentes de lenguas, de espacios de discusión y análisis de los retos que traen las nuevas realidades digitales, informáticas y mediáticas, al igual que las posibilidades de las nuevas plataformas de comunicación multimodal existentes.

\section{Multimodalidad}

Con el arribo de la llamada era digital, la multimodalidad se hace evidente, pues los sistemas de 
comunicación digital les permiten a las personas interactuar de manera multimediática en sus comunicaciones cotidianas de manera natural. Es decir, cuando una persona envía un mensaje en una red social con un texto verbal, unos cuantos emoticones, una foto y una canción, está construyendo un complejo mensaje multimodal que no es objeto de una reflexión profunda y que se ve como natural. Si a esto le sumamos las formas de interacción deliberadamente complejas, como las plataformas diseñadas y dedicadas a la enseñanza de una disciplina particular, podemos ver cómo la multimodalidad ha llegado para quedarse. Así pues, en palabras de Kress y van Leeuwen:

Today, however... the different modes have technically become the same at some level of representation, and they can be operated by one multi-skilled person, using one interface, one mode of physical manipulation, so that he or she can ask, at every point: 'Shall I express this with sound or music?, 'Shall I say this visually or verbally? And so on (2001, p. 2).

La era digital ha planteado la multimodalidad como una cuestión de reflexión y una necesidad práctica en los procesos de enseñanza-aprendizaje de las lenguas, debido a que es claro que la relación que tienen los individuos hoy con las diversas posibilidades multimodales tiende a ser cada vez más fluida e inconsciente. Se trata de incluir estas interacciones multimodales en el aula con fines pedagógicos, con el objetivo de que los docentes se conviertan en los facilitadores de una nueva forma de ver la interacción virtual, ya no exclusivamente como una forma de entretenimiento o de recolección de información, sino como una herramienta eficaz para desarrollar contenidos específicos de manera novedosa e interesante para personas que viven inmersas en un mundo de interacciones digitales.

Con base en la teoría del aprendizaje que postula que debe existir tanto una buena retención de la información como una buena transferencia, en el sentido de la apropiación crítica y analítica de los conceptos para que exista un aprendizaje significativo (Farías, Obilinovic y Orrego, 2010), se puede plantear que la enseñanza de lenguas por medio del uso de herramientas multimodales puede fortalecer los procesos cognitivos de los estudiantes. Estas herramientas implican tanto el procesamiento de lenguaje verbal, como el procesamiento de imágenes que, tal parece, se realimentan. También, se plantea que los estudiantes aprenden mejor cuando hay una interacción entre narración y animación en la pantalla.

Esta nueva visión del desarrollo de material pone al docente en posición de autor de sus propios materiales de clase y no como usuario de materiales diseñados de manera genérica. Esto quiere decir que su clase podrá ser diseñada de manera más contextualizada al tener en cuenta las características específicas del grupo con el cual está trabajando. Asimismo, le va a permitir poner en práctica el principio básico de la construcción conjunta del conocimiento que prevalece en los nuevos modelos pedagógicos, pues tanto el docente como el estudiante deben construir herramientas, interactuar, realizar tareas y resolver problemas de maneras siempre nuevas y con modos de interacción diversos.

Cuestas y Valotta (2011) proponen varios tipos de actividades que involucran la creación de diálogos, folletos turísticos, fotografía, video, utilización de redes sociales virtuales, música, etc. Estas actividades se pueden adaptar a diferentes poblaciones, niveles de lengua y grupos etarios. La clase se puede entender como un espacio en donde el aprendizaje multimodal se utiliza de manera efectiva para interactuar con formas de comunicación diferentes a la textual, la que se ha utilizado tradicionalmente. Cabe anotar que la mayoría de los docentes de lenguas ya utilizan la multimodalidad en sus clases, pues los textos musicales, las imágenes y demás recursos no verbales son usados con frecuencia. Ahora, se trata de incluir la mayoría de recursos que provee la cultura digital en la cual estamos inmersos: imágenes, videos, chats, entradas de blogs, comentarios 
en redes sociales, conferencias en la red, interacciones en tiempo real en audio o video, etc.

Por otra parte, Martínez (2013) plantea que los métodos de evaluación de las aproximaciones multimodales a la enseñanza de lenguas deben incluir diversas formas del lenguaje formal y dar cabida a otros medios de comunicación digital, mediática e informática. Así es que plantea el portafolio como una manera más adecuada de evaluar, pues tiene el potencial de incorporar múltiples modos de comunicación. Además, el desarrollo del portafolio favorece el aprendizaje autónomo y fomenta la creatividad por parte de los estudiantes.

Finalmente, vale la pena decir que la hipertextualidad de los textos multimodales que se pueden encontrar en la web, como los blogs, podría ser de mucha utilidad, cuando es guiada hacia un objetivo concreto y bien delimitado. De no ser así, el estudiante puede perderse en un mar de hipervínculos que lo pueden llevar muy lejos del texto original sin establecer relaciones lógicas o procesos de intertextualidad. Peor aún, pueden pasar por esos hipertextos de manera consecutiva sin mayor esfuerzo, lo que podría derivar en resultados limitados o nulos para su proceso de aprendizaje (Pujolà y Montmany, 2010).

\section{Conclusiones}

La revisión teórica realizada en este artículo sugiere que, como resultado tanto de la creciente presencia de las TIC como del vertiginoso desarrollo de la pedagogía en lenguas, es necesario examinar los procesos de formación docente que estas conllevan, con el propósito de reinterpretar y redireccionar las propuestas formativas de las facultades de educación, los programas de licenciatura y los procesos de cualificación docente. Esta reinterpretación exige pensar el trabajo sistemático, con profesores en formación y en ejercicio, de la adquisición de habilidades que les permita entender e implementar nuevas prácticas y procesos de comunicación basados en el posmétodo y las comunidades de práctica. Igual- mente, requiere la incorporación de marcos conceptuales más comprensivos que hagan viable apuestas formativas centradas en el desarrollo metódico de una serie de competencias profesionales basadas en la multimodalidad y la multialfabetización.

En los apartados anteriores se ha hecho énfasis en el rol de cada una de las tendencias pedagógicas en la formación de los docentes en general y de los docentes de lenguas tanto materna como extranjera en particular. Estos planteamientos se pueden sintetizar al afirmar que los programas de pregrado y posgrado deben adaptarse de tal manera que permitan formar docentes en lenguas con las siguientes características:

Todo profesor de lenguas debe conocer las teorías expuestas de manera profunda, pero no solo las teorías, sino su aplicación práctica en el aula; es decir que la diferenciación curricular entre teoría y práctica, por lo menos en este campo, se debe reducir o debe desaparecer totalmente. Esto implica que a medida que se estudian las teorías, se ponen en práctica en el aula, lo cual invita a que haya una integración muy bien coordinada entre la práctica y las ideas pedagógicas que se trabajen durante el proceso de formación del docente.

Para propiciar la participación de los estudiantes en comunidades de práctica, tanto presenciales como virtuales, que les permita poner en ejercicio sus conocimientos, los docentes deben estar familiarizados con dichas comunidades, y deben, en la medida de lo posible, participar en comunidades de práctica profesionales que hagan posible la reflexión sobre su quehacer profesional.

El manejo de mensajes multimodales es imprescindible. La interacción entre textos verbales escritos, orales, imágenes, videos, música, etc., debe ser parte del acervo del docente. También debe ser consciente de la importancia de incluir diversos dialectos, sociolectos y demás variedades lingüísticas usadas en la lengua objetivo. 
Los docentes deben tener una formación sólida en manejo de las TIC; deben saber manejar tanto las plataformas comerciales de interacción como Facebook, Skype, Twitter, YouTube, etc., como las plataformas que tienen fines académicos como Writingmatrix, Moodle, Blackboard, o cualquiera que haya diseñado o esté utilizando la institución en la cual trabajan o estudian. Su manejo debe ser lo suficientemente fluido para poder guiar a los estudiantes en el uso de las plataformas académicas propiamente dichas, y, por ejemplo, en la construcción de un blog para la clase.

Para lograr lo anterior, el docente de lengua materna y extranjera debe estar empoderado a fin de que, a través de la reflexión, critique continuamente sus propias ideas de manera rigurosa y diseñe estrategias de planeación, ejecución y evaluación de todo tipo de prácticas profesionales, desde las más amplias hasta las más específicas en el aula. Con programas de formación basados o enmarcados en el posmétodo; las comunidades de práctica, la multialfabetización y la multimodalidad; los procesos de enseñanza sobre lengua, cultura, discurso y comunicación pueden resultar ser más innovadores, lo cual tiene el potencial de cualificar el quehacer docente en el salón de lenguas. En últimas, la inclusión de estos nuevos discursos en la formación docente de profesores de lengua materna y extranjera en programas de pregrado y posgrado puede permitir a nuestra comunidad académica reconfigurarse, lo cual nos puede, como lo describía Vez (1994), animar a:

...imaginar la innovación como un río de conocimiento que nos atrae con el frescor de sus aguas y nos anima a zambullirnos en él, a fin de renovar y reavivar nuestras fuerzas, a la vez que nos desprendemos del polvo de nuestras rutinas profesionales, acumulado durante largo tiempo en nuestra piel (p.5).

\section{Referencias}

Adler, S. (2004). Introduction. En Adler, S. (ed.). Critical issues in social studies. Teacher education (pp. 1-7). USA: Information Age Publishing Inc.

Álvarez, A. y León, A. (2008). ¿Para qué formar maestros? En M. González (comp.), Paradojas en la formación docente: elementos para avanzar en su reflexión y planteamiento de propuestas (pp. 59-68). Bogotá: Instituto para el Desarrollo y la Innovación Educativa (IDIE).

Arnáez, P. (2006). La lingüística aplicada a la enseñanza de la lengua: una línea de investigación. Letras, 48 (73), 349-363. Recuperado el 13 de agosto de 2014 de http://www.scielo.org.ve/scielo.php?script=sci_arttext\&p $\mathrm{id}=$ So $459-12832006000200005$

Arnáez, P. (2013). La enseñanza de la lengua desde la perspectiva del docente. Paradigma, 34 (2), 7-29. Recuperado el 13 de agosto de 2014 de http://www.scielo.org.ve/pdf/pdg/v34n2/arto2.pdf

Cárdenas, R. (2009). Tendencias globales y locales en la formación de docentes de lenguas extranjeras. íKALA: Revista de Cultura y Lenguaje, 14 (22), 71-106. Recuperado el o5 de septiembre de 2014 de http://aprendeenlinea.udea.edu.co/revistas/index.php/ikala/article/view/2634/2121 
ISSN 0123-1294 | Educ.Educ. Vol. 19. No. 1 | Enero-Abril de 2016 | pp. 46-64.

Universidad de La Sabana | Facultad de Educación

Cochran-Smith, M., Barnatt, J., Friedman, A. y Pine, G. (2009). Inquiry on inquiry: Practitioner research and student learning. Action in Teacher Education, 31 (2), 17-32. Recuperado el o5 de septiembre de 2014 de http:// www.tandfonline.com/doi/abs/10.1080/01626620.2009.10463515\#.VMF6HGP_za4

Cochran-Smith, M. y Zeichner, K. (2009). Studying teacher education. The report of the AERA panel on research and teacher education. USA: Lawrence Erlbaum Associates Publishers.

Cope, B. y Kalantzis, M. (2010). "Multialfabetización": nuevas alfabetizaciones, nuevas formas de aprendizaje. Boletín de la Asociación Andaluza de Bibliotecarios, 98-99, 53-91. Recuperado el o5 de septiembre de 2014 de https://dialnet.unirioja.es/descarga/articulo/3616427.pdf

Cruz-Arcila, F. (2013). Accounting for difference and diversity in language teaching and learning. Revista Educación y Educadores, 16 (1), 80-92.

Cuestas, A. D. y Valotta, M. E. (2011). Alumnos y docentes 2.0: Interacción y multimodalidad en la enseñanza de las lenguas extranjeras. Puertas Abiertas, (7), 1-12. Recuperado el 15 de septiembre de 2014 de www.memoria.fahce.unlp.edu.ar/art_revistas/pr.5741/pr.5741.pdf

Díaz-Corralejo, J. (2002). Reflexiones sobre la didáctica de la enseñanza/aprendizaje de la Lengua y la Literatura. Arbor, 173 (681), 129-152. Recuperado el 15 de septiembre de 2014 de http://arbor.revistas.csic.es/index.php/ arbor/article/view/1112/1119

Emilson, E. (2013). Perspectiva multilingüe y multicultural en la formación de docentes de inglés como lengua extranjera. En Preciado, B., Solares Rojas, A., Sandoval Cáceres, I. T.y Butto Zarzar, C. (eds.), Addendum. Proceedings of the first Meeting between the National Pedagogic University and the Faculty of Education of the University of Calgary (pp. 9-15). Canada: Faculty of Education of the University of Calgary.

Fandiño, Y. (2010). Research as a means of empowering teachers in the 21st century. Revista Educación y Educadores, 13 (1), 109-124. Recuperado el 12 de noviembre de 2014 de http://educacionyeducadores.unisabana. edu.co/index.php/eye/article/view/1624/2134

Farías, M., Obilinovic, K. y Orrego, R. (2010). Modelos de aprendizaje multimodal y enseñanza-aprendizaje de lenguas extranjeras. Universitas tarraconensis: Revista de Ciències de l'Educació, 16 (2), 55-74.

Feiman-Nemser, S. (1990). Conceptual orientations in teacher education (Report number SP 032 537). Marion, IN: Indiana Wesleyan Center for Educational Excellence. Retrieved from ERIC database (ED323177). Recuperado el 11 de noviembre de 2014 de http://files.eric.ed.gov/fulltext/ED323177.pdf

Flores, J. y López, S. (2011). Formación de los docentes para la enseñanza de la lengua desde el enfoque comunicativo. El caso de la Universidad Pedagógica Nacional de México. Odiseo - Revista Electrónica de Pedagogía, 88 (16). Recuperado el 12 de noviembre de 2014 de http://odiseo.com.mx/bitacora-educativa/2011/06/ formacion-docentes-para-ensenanza-lengua-desde-enfoque-comunicativo-caso

Foppa, C. T. (2011). O ensino reflexivo na era do pós-método: um estudo entre profesores de línguas de cursos libres. Revista Caminhos em Lingüistica Aplicada, 4(1), 69-88. Recuperado el 12 de noviembre de 2014 de http://periodicos.unitau.br/ojs-2.2/index.php/caminhoslinguistica/article/viewFile/1138/954 
Freeman, D. (1991). Three views to teachers' knowledge. IATEFL Teacher Development Newsletter, December, 1-4.

Glatthorn, A. (1995). Teacher development. En Anderson, L. (ed.), International Encyclopedia of Teaching and Teacher Education (2nd edition, pp. 41-57). London: Pergamon Press.

González, A. y Quinchía, D. (2003). Tomorrow's EFL teacher educators. Colombian Applied Linguistics Journal, 5 , 86-104. Recuperado el 24 de septiembre de 2014 de http://revistas.udistrital.edu.co/ojs/index.php/calj/ article/view/183

Hourdequin, P. (2012). Identity and communities of practice in foreign language learning contexts. Teachers College, Columbia University Working Papers in TESOL \& Applied Linguistics, 12 (2), 133-162. Recuperado el 24 de septiembre de 2014 de http://tesol-dev.journals.cdrs.columbia.edu/wp-content/uploads/sites/12/2015/04/8.Hourdequin-2012.pdf

Johnson, K. (2009). Trends in second language teacher education. In Burns, A.y J. Richards (eds.), Second language teacher education (pp. 20-29). Cambridge: Cambridge University Press.

Kress, G.y van Leeuwen, T. (2001). Multimodal discourse: The modes and media of contemporary communication. UK: Oxford University Press.

Kumaravadivelu, B. (2003). Beyond methods: Macrostrategies for language teaching. New Haven: Yale University Press.

Londoño, G. (2003). La enseñanza de la lengua materna. Un reto para el docente, del decir al hacer. Revista hechos y proyecciones del lenguaje, 13 (1), 9-18.

Loughran, J. (2006). Developing a pedagogy of teacher education. Understanding teaching and learning about teaching. New York: Routledge Taylor \& Francis group.

Martínez, M. (2008). Innovar e investigar: dos modos de visibilizar el posicionamiento y empoderamiento del docente. Magazín Aula Urbana, 70. Recuperado 13 de noviembre de 2014 de http://www.idep.edu.co/pdf/ aula/MAU\%2070.pdf

Martínez, M. (2013). Experiencia de enseñanza multimodal en una clase de idiomas. ENSAYOS: Revista de la Facultad de Educación de Albacete, 28, 1-12. Recuperado el 24 de septiembre de 2014 de www.revista.uclm.es/ index.php/ensayos

Meneghini, C. (2009). A perspectiva pós-método e a tecnología no ensino de línguas. Recuperado 13 de noviembre de 2014 de https://ensinodelinguas.wikispaces.com/file/view/Artigo+1.pdf

Ministerio de Educación Nacional. (2006). Estándares básicos de competencias en lenguaje, matemáticas, ciencias y ciudadanas. Bogotá: MEN.

Pérez, M., Barrios, M. y Zuluaga Z. (2010). ¿Cómo se enseña lenguaje en Colombia? Revista Palabra, 10 (24), 6-8. 
Pujolà, J. T. y Montmany, B. (2010). Más allá de lo escrito: la hipertextualidad y la multimodalidad en los blogs como estrategias discursivas de la comunicación digital. En Pérez, J. (coord.), Alfabetización mediática y culturas digitales (pp. 140-153). Sevilla: Gabinete de Comunicación y Educación.

Richards, J. (1998). Beyond training. Cambridge: Cambridge University Press.

Romanish, B. (1993). Teacher empowerment as the focus of school reforming. The School Community Journal, 3 (1), 47-60. Recuperado el 13 de noviembre de 2014 de http://www.adi.org/journal/ss93/RomanishSpring1993.pdf

Short, P. (1994). Defining Teacher Empowerment. Education, 114 (4), 488-492.

The New London Group (2000). A pedagogy of multiliteracies: Designing social futures. In Cope, B. \& Kalantzis, M. (eds.), Multiliteracies: Literacy learning and the design of social futures (pp. 9-37). New York, NY: Routledge.

Unesco. (1990). Innovations and initiatives in teacher education in Asia and the Pacific region. Bangkok: Unesco Principal Regional Office for Asia and the Pacific. Recuperado el 13 de noviembre de 2014 de http://www. unesco.org/education/pdf/412_35a.pdf.

Usma, J. (2009). Education and language policy in Colombia: Exploring processes of inclusion, exclusion, and stratification in times of global reform. Profile Issues in teachers' professional development, 11, 123-141. Recuperado el 13 de noviembre de 2014 de http://www.revistas.unal.edu.co/index.php/profile/article/viewFile/10551/11014

Vez, J. M. (1994). Pensar la innovación en el aula de lengua extranjera. Aula de Innovación Educativa, 33, 5-11. Recuperado el 5 de noviembre de 2015 de http://www.grao.com/revistas/aula/o33-la-ensenanza-de-lenguas-extranjeras--centros-abiertos-al-barrio/pensar-la-innovacion-en-el-aula-de-lengua-extranjera

Vieira, I. y Moreira, M. A. (2008). Reflective teacher education towards learner autonomy: building a culture of possibility. En Raya, M. y Lamb, T. (eds.), Pedagogy for autonomy in language education: Theory, practice and teacher education (pp. 266-282). Dublin: Authentik.

Villegas-Reimers, E. (2002). Teacher preparation: International perspective. Encyclopedia of Education [online]. Recuperado el 5 de noviembre de 2015 de http://www.ency clopedia.com/doc/1G2-3403200613.html.

Villegas-Reimers, E. (2003). Teacher professional development: An international review of the literature. Paris: IIEPUnesco. Recuperado el 5 de noviembre de 2015 de http://unesdoc.unesco.org/images/o013/001330/133010e.pdf

Whitehead, J. (1989). Creating a living educational theory from questions of the kind, how do I improve my practice? Cambridge Journal of Education, 19 (1), 41-52.

Yang, S. H. (2008). Using blogs to enhance critical reflection and community of practice. Educational Technology and Society, $12(1), 11-21$.

Zuluaga, O. (1999). Pedagogía e historia: la historicidad de la pedagogía, la enseñanza, un objeto de saber. Bogotá: Siglo del Hombre Editores. 